\title{
Dynamic load management in a smart home to participate in demand response events
}

\author{
Filipe Fernandes, Hugo Morais, Zita Vale, Carlos Ramos
}

\begin{abstract}

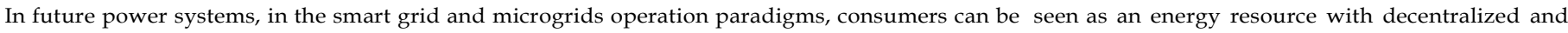

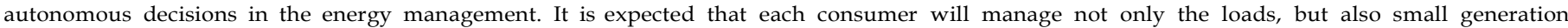

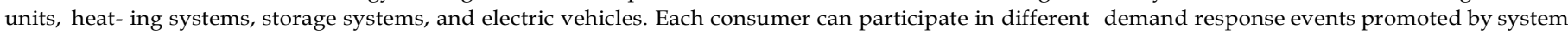

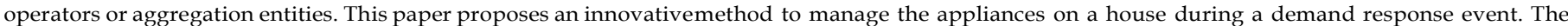

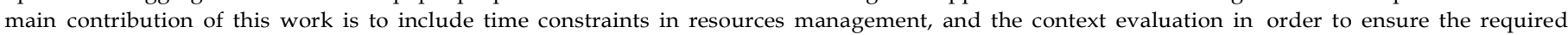

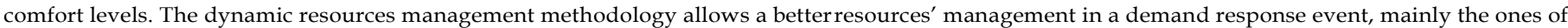

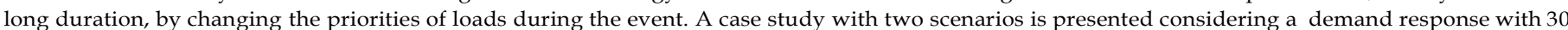

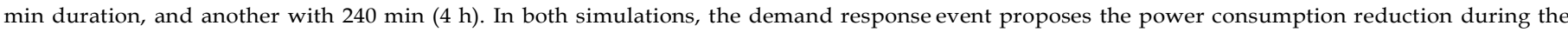
event. A total of 18 loads are used, including real and virtual ones, controlled by the presented house management system.
\end{abstract}

Keywords:

Demand response, Dynamic load priority, Domestic consumer, Energy resources management.

\section{Introduction}

In the new electrical networks operation paradigm, consumers will be seen as active resources with capability to manage their energy consumption, energy generation, and energy storage systems. To implement this vision, several approaches have been proposed with the main focus on the concepts of smart gridsand microgrids [1]. The development of smart grids requires, at the same time, the development of new other concepts such as the smart meter or the smart home.

A smart home can be defined as a house which comprises a network communication between all devices of the house allowing the control, monitoring and remote access of all applications and services of the management system. The management system should include advanced functions, such as the management of electric vehicles, the interface with external operators, security functions, health care prevention, and among others [2,3]. According to [4], to be considered smart, a home should include three main elements: the internal communication network, intelligent control systems, and home automation. In our opinion, this concept should be extended in order to integrate external communications. In fact, the house management system should be capable of interacting with external entities such as services aggregators, utilities, and health entities, among others, making decisions according to these interactions. The automatic participation in demand response(DR) events is an interesting example. In DR events, the house management system should reduce the electricity consumption based not on internal information, but on the interaction with an external entity.

The complexity of the house management systems (HMS) should be significantly increased in a near future. HMS should be able to manage effectively the total consumption, distributed generation units, electric vehicles, and also the participation in demand response events. On the other hand, the HMS should consider the consumption efficiency, the minimization of the energy bill, and the required comfort levels in the operation context [5]. The smart home system should provide the required comfort level in each context considering the minimum energy consumption and the minimum operation costs, including the maintenance [6]. To improve the performance of the house management systems, it is necessary to include the ability to autonomously acquire 


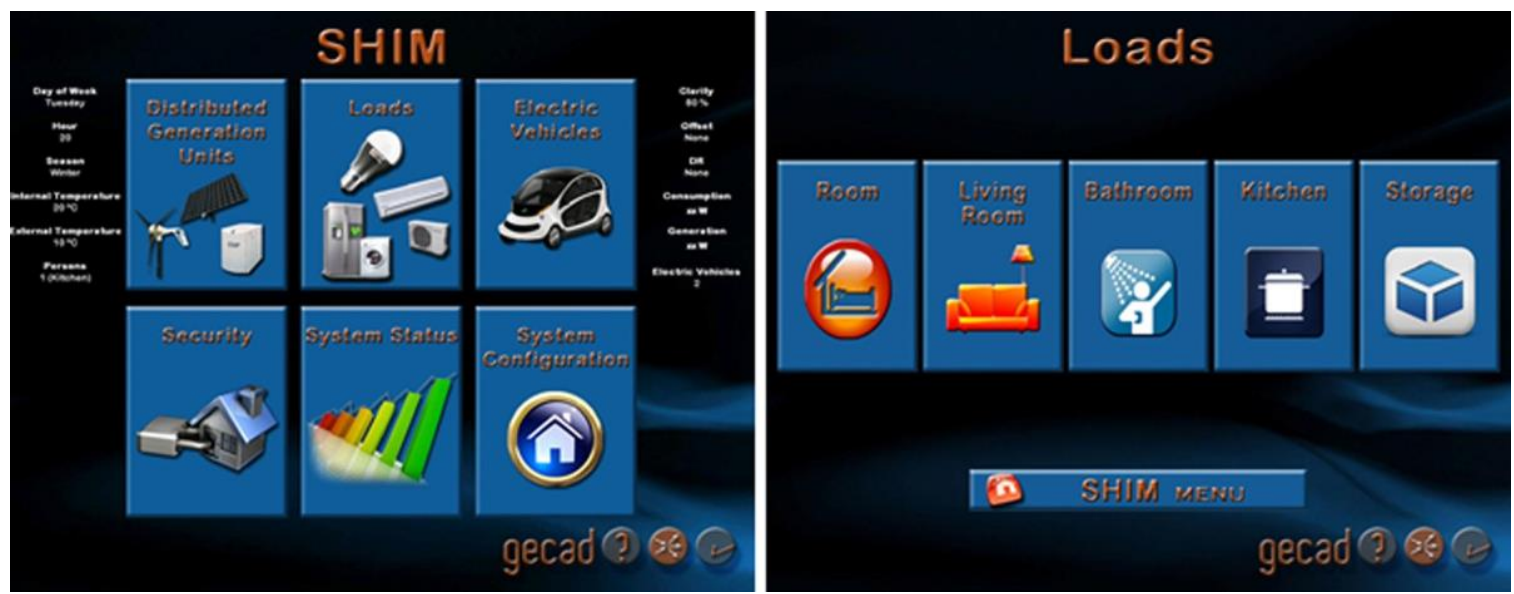

Fig. 1. SHIM user interface.

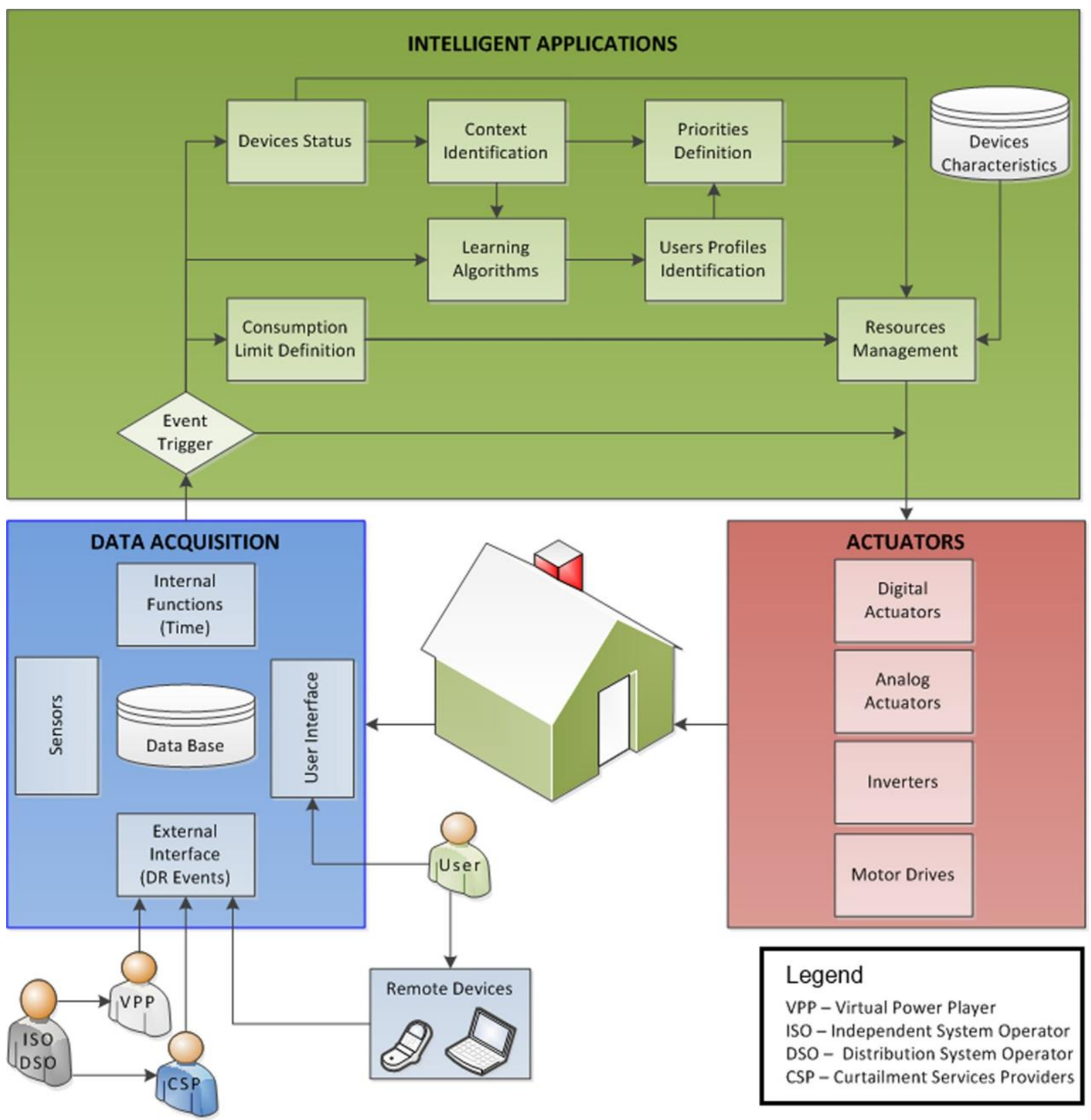

Fig. 2. Architecture of the intelligent energy management. 


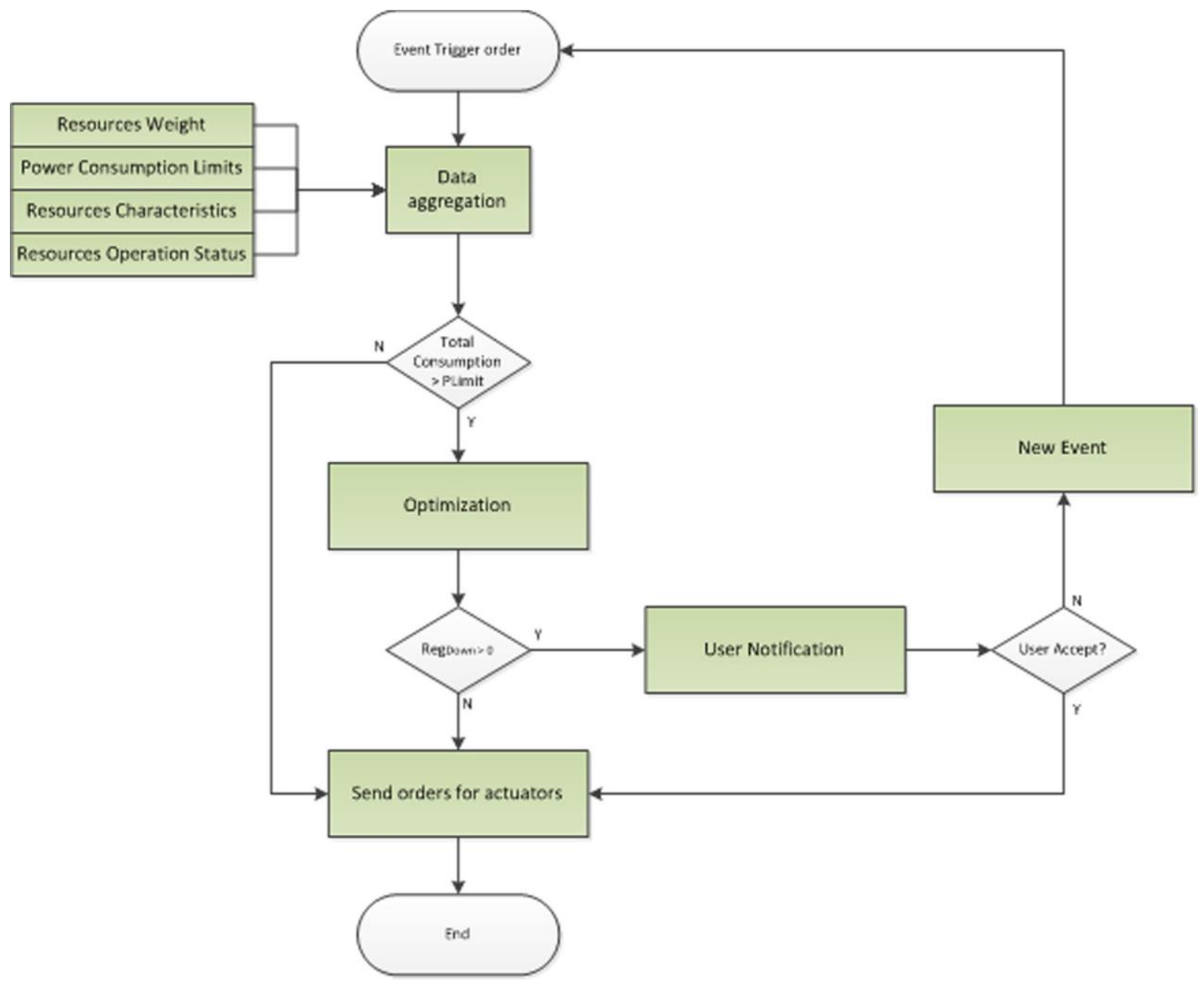

Fig. 3. Description of the resources management module.

knowledge on the user's behavior adjusting the consumer's preferences (profiles) during the management process, improving the global system performance, and the consumers' satisfaction [7]. This characteristic will be very important to the control of devices during a demand response event in order to reduce the electricity consumption without changing the comfort levels too much [8].

In this paper an innovative energy management method to be included in the Supervisor Control and Data Acquisition House Intelligent Management (SHIM) [9] is proposed. SHIM is a simulation platform developed and implemented in the Knowledge Engineering and Decision Support Research Center (GECAD). SHIM works as a HMS with some advanced functions that allow the control of real hardware, namely real loads, batteries, photovoltaic panels, wind generation, and other devices. Other interesting feature of SHIM is the possibility of managing real and virtual loads in the same simulation. On the other hand, SHIM is included in a smart grids simulation platform based on multi-agent systems called Multi-Agent Smart Grid Simulation Platform (MASGriP) [10]. In fact, MASGriP integrates several SHIM, one in each consumer agent. Theintegration ofSHIMinMASGriPallows thesimulation of more complex tasks, such as demand response events promoted by the system operators or by the aggregators implemented in MASGriP, like the virtual power players (VPP) or the curtailment service providers (CSP). Several types of demand response programs have been proposed by different systems operators in order to try to develop adequate programs for different situations. According to
[11], the load curtailment in the demand response programs can vary between $15 \mathrm{~min}$ and more than $5 \mathrm{~h}$.

The structure of this paper begins with the introduction in Section 1 . Section 2 introduces several concepts and methods used in the energy management systems, in the domestic consumers' context. Section 3 describes the methodology proposed in the paper for the intelligent management system to participate automatically in the DR events. Section 4 presents the main results of the case study considering the loads used in the simulation and the characterization of the scenarios tested. The main conclusions are presented in the last section, as well as the main contribution of the work.

\section{Energy management concepts}

The increase of energy and of electricity consumption makes the effectiveness counteract actions essentials $[12,13]$. To improve the efficiency of the residential sector, it is important to disaggregate consumptions by floor, room, and device to evaluate the devices' efficiency, as well as the expected consumption behavior $[14,15]$. The replacement of inefficient devices for more efficient ones can decrease the energy consumption. However, the energy consumptions monitoring is important in large time periods in order to quantify the replacement advantages. In the following subsections, the house energy management systems will be discussed in detail providing more information on intelligent applications, and on the management of demand response events from the house's point of view. 


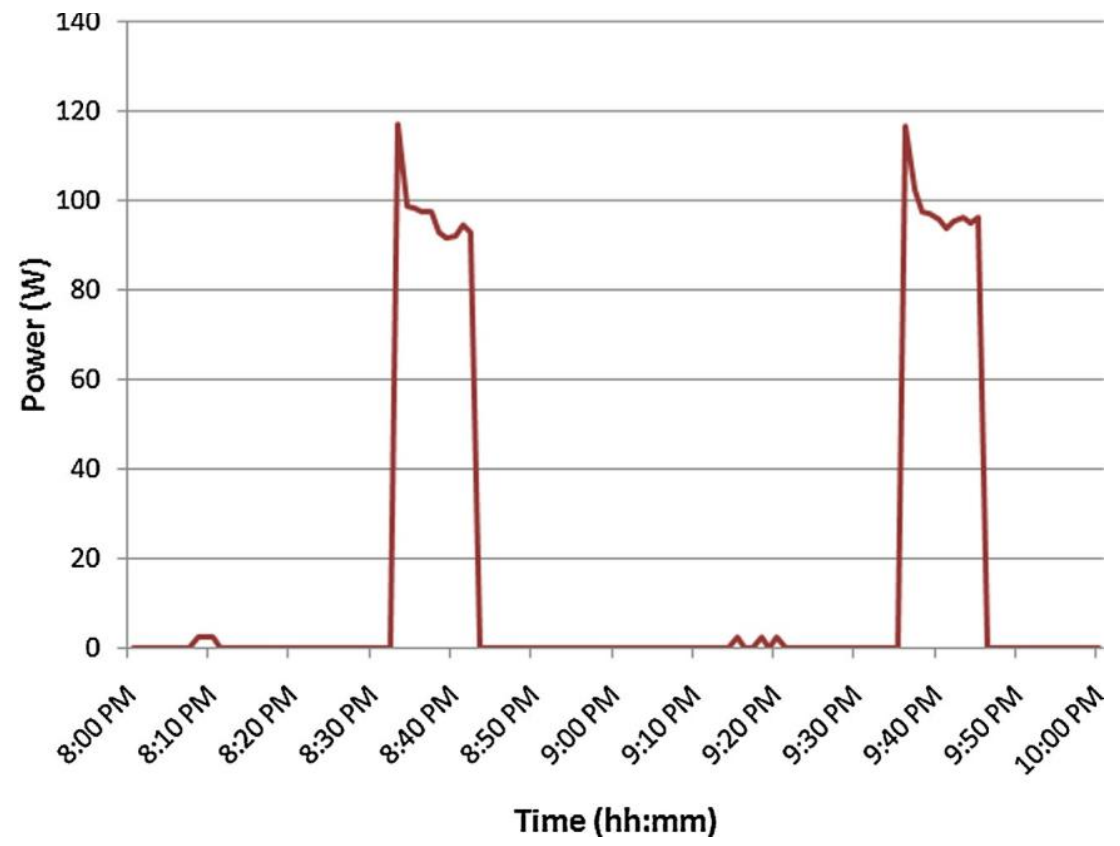

Fig. 4. Refrigerator load profile between 8:00 PM and 10:00 PM.

\subsection{House energy management systems}

House management systems are not a new concept. In [16], a HMS is proposed focusing on the monitoring, controlling and management aspects with the objective of defining the electricity consumption user's profiles to identify weak behaviors. The first HMS systems are focusing on implementation aspects. However, the use of intelligent applications in home automation through micro-controllers is proposed in [17], and some advanced methodologies concerning the use of more accurate communications, protocols and control methods to improve the robustness of the HMS are presented in [18].

Many advances were proposed in order to improve HMS systems, such as the existence of integrated residential gateways [19] or the use of home internet network in HMS systems [20]. More features are proposed in [21], namely the use of wireless communication and the remote access to monitor and control house devices. The use of user location, user motion detection, and measurement/control devices in house's electricity sockets is proposed in [22], in order to determine the user's consumption profile. Besides other features, this system allows turning off some devices when rooms are empty (without persons).

Besides the electricity consumption management, in [23] a HMS capable of joining the management of electricity and gas consumption is proposed. In [23], it also addressed the user's active participation and the contribution for a better performance/efficiency of the system. In [13], electricity consumption profiles collected according to several factors which influence the consumption are analyzed, such as the comfort levels or the weather. This work allows a better understanding of the consumption behavior of consumers with different profiles, different necessities, and in different use contexts.

Currently, several HMS solutions are proposed for companies and organizations. However, the massive use of HMS is still not a reality. In [24] are appointed some barriers to the massive use of HMS, namely users that are not aware of the existing technologies; high prices of the existing solutions; and the weak users' interfaces proposed in HMS. These barriers represent opportunities to the development of new methodologies to integrate in the HMS, as well as in the development of new HMS.

\subsection{Management of demand response events in house management systems}

Demand response (DR) programs can be an important energy resource in the future power systems. Large consumers (industry and large commerce) are the main focus of the actual DR programs. However, small consumers, including the domestic ones, can provide more a flexible response in these events [25]. The management of DR events in the HMS is an important challenge for future HMS, in order to take monetary advantages from the participation in DR events. The future house management systems should be able to manage automatically demand response events considering the consumers' point of view, regarding the consumption/prices off sets, and the loads preferences [26].

Several types of demand response are available being the Time-of-Use (TOU) programs the most popular. TOU encourage consumers to decrease the consumption in response to a higher electricity price [27]. The participation in DR programs can be managed by an aggregator entity, for instance by the curtailment service provider (CSP). The CSP can manage the participation in demand response events of more than one consumer, making some guaranties to the system operators, and providing services to the consumers.

In [28] it is proposed that communication architecture is composed of different layers, considering a layer to implement the interface between the HMS, and the system operator energy management system. The loads management was implemented in another layer using a mixed-integer programming in order to minimize the operation costs considering the demand response opportunities.

\subsection{State of the art summary and main contributions}

The active participation of consumers in the future power system management is one key issue for their success. To achieve these challenges, more intelligent and adaptive house management systems should be used in order to ensure an appropriate response to the operation system's needs. The research and development activities concerning the house management systems are focused on their architecture, protocols, security, and efficiency management. 


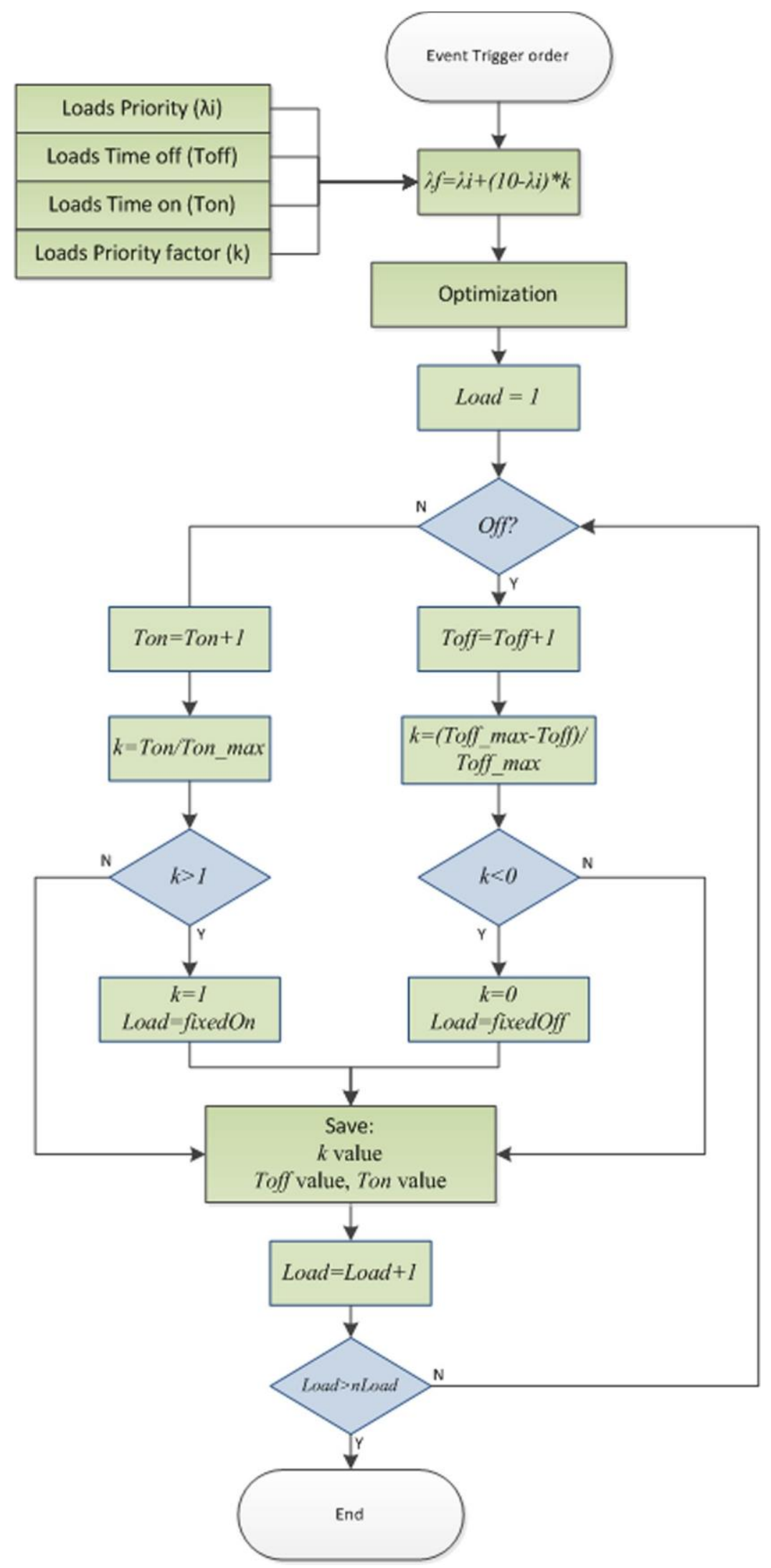

Fig. 5. Dynamic loads priority method for each period of the optimization process. 


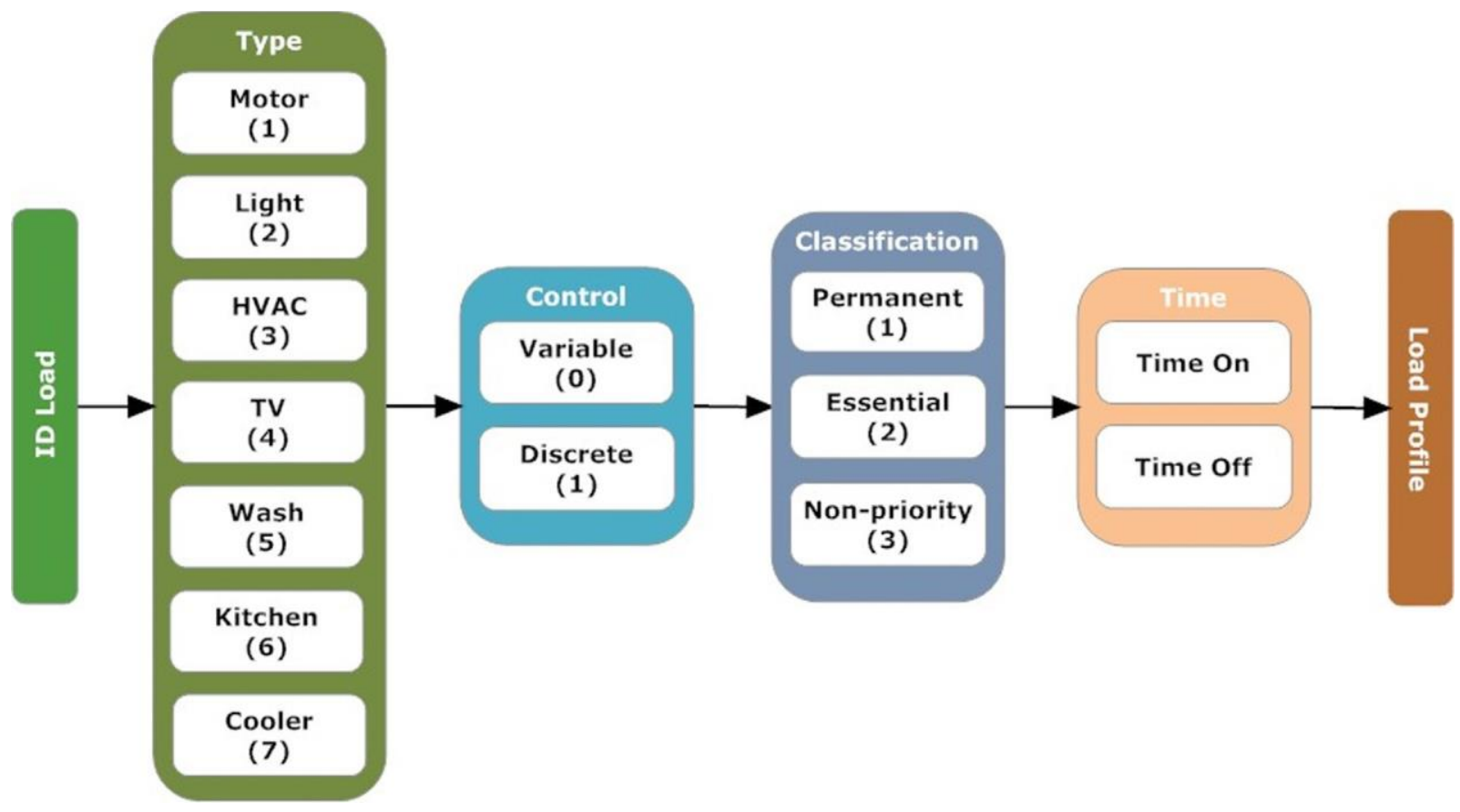

Fig. 6. Diagram to identify the characteristics of the load in a management event.

However, thefutureHMSshould becapableofcommunicatingwith the utilities management systems, improvising the global system reliability, effectiveness and efficiency and, from the consumer's point of view, the reduction of the energy bill.

The management of demand response programs in intelligent house management systems is one of the most important interaction mechanisms between consumers and system operators. One of the main challenges is to participate in the DR events ensuring the comfort levels required by users. In [29], the interactions between domestic consumers and the system operator are presented considering the real-time prices demand response. The price base demand response represents an opportunity for consumers, yet it does not impose hard constraints in the power consumption. This type of events requires several studies from the system operator in order to understand the consumption elasticity of each consumer in each operation context. The work presented in [30] proposes an algorithm to manage four loads keeping the total power consumption below different limits according to the DR events. The algorithm is performed in realloads. However, theload curtailmentis processed in the beginning of the demand response event, and it is kept during the event.

The main contributions of the present paper are:

1. The dynamic load management algorithms implementation in house management systems allowing better performances of the global system during a demand response event. In the proposed methodology, the load curtailment scheduling is adapted every minute, ensuring adequate comfort levels during the event, mainly in demand response of long time duration.

2. Theproposed methodology includes theoperatingrequirements of the equipment in order to define the minimum time of functioning during the demand response event. These requirements have been included in the optimization methodology in order to obtain a dynamic scheduling during the DR event, and not a constant scheduling for all events.

3. The proposed methodology alsoconsiders the contextidentification and the user's profiles inputs to adjust the load curtailment schedule.
4. Furthermore, the proposed methodology considers the interaction with the users during the demand response event, given more flexibility to the proposed HMS.

\section{Dynamic load management algorithms during a demand response event}

To allow an active participation of consumers in the power systems management, the future HMS should be able to participate automatically in demand response events. The participation in DR events means the reduction of the electricity consumption during the event. To guarantee the consumption reduction, the HMS can cut or reduce some loads consumption, improve the power generation or re-schedule the electric vehicles charge/discharge processes. All these resources are implemented in the SHIM system.

The SHIM system has been developed in the Intelligent Energy Systems Laboratory (LASIE), located at the Institute of Engineering-Polytechnic of Porto (ISEP/IPP). SHIM is a testbed platform with the main goal of testing, simulating, and validating new algorithms and methodologies to apply into house/buildings' management. SHIM has real equipment such as several types of

loads, distributed generation (photovoltaic panels, wind generator), and storage systems that allow the simulation of the electric vehicles' behavior. SHIM is part of a large simulation platform based in multi-agents systems. Multi-Agent Smart Grid Simulation Platform (MASGriP) is a test platform that simulates a competitive environment in future power systems [10]. SHIM is included in consumers' agents in MASGriP. In complex scenarios, several consumers are included in the simulations, and consequently several SHIM systems are simulated at the same time. To ensure the simulation of big scenarios, SHIM is able to control real loads and virtual loads simulating the characteristics of the real ones.

SHIM is composed of different modules, each one with different functions. The context identification module includes algorithms to characterize the actual use context considering different aspects, such as the weather, the time of day, the day of the week, the external temperature, the session, the user inside the house, and among others. The user's profiles module includes comfort levels offsets 


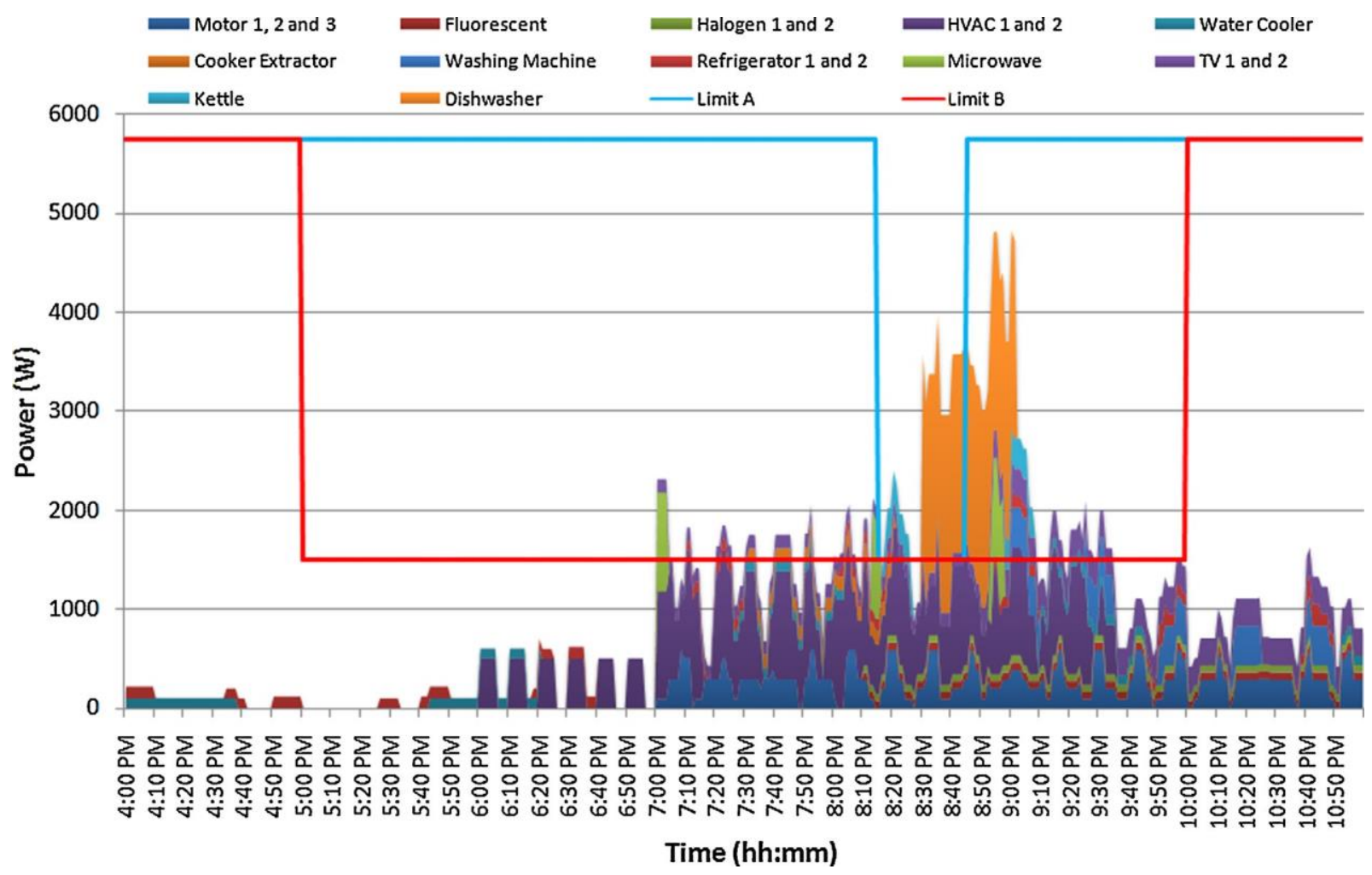

Fig. 7. The power consumption for the Base Scenario without power limits.

for each user, as well as the user's preferences. The learning module includes learning algorithms to identify the changes in the user's behaviorduring the systemuseperiod (years). Thelearningmodule changes the users' profiles according to the feedback of the interaction between users and the system [31]. The optimization module includes several algorithms considering the operation in different contexts, and theexistenceof differentresources. Afterwards, SHIM has control management modules able to communicate with load actuators, and with generation and storagesystemsinverters.SHIM allows using different user interfaces platforms namely touch panels, android devices, and remote computers. Fig. 1 shows some displays ofSHIMuserinterface.

In this paper, an innovative optimization algorithm considering a dynamic load management during a DR event is proposed and introduced in the SHIM system, increasing its functionality. The proposed methodology extends the SHIM capability concerning the participation in demand response, mainly in the long duration events, ensuring higher comfort levels than the previously implemented methodologies.

Several demand response programs can be implemented by system operators considering different aspects for participating in the programs. DR programs can be executed in periods of $15 \mathrm{~min}$ to several hours. From the house point of view, it is necessary to develop different methodologies to participate in different DR events. For example, it is possible to disconnect the air conditioning or a refrigerator during $15 \mathrm{~min}$, but it is impossible to disconnect this equipment for $5 \mathrm{~h}$.

\subsection{Smart house intelligent management simulation platform}

TheSHIM platformiscomposed of differentmodules, eachmodule being composed of different algorithms to be used in different

Table 1

Information to identify the characteristics of the loads in the domestic consumer.

\begin{tabular}{|c|c|c|c|c|c|c|c|c|}
\hline Load & SHIM control & ID load & Type & Control & Classification & Ton & Toff & $T$ \\
\hline Motor 1 & Real & 1 & 1 & 0 & 2 & 9 & 4 & 13 \\
\hline Motor 2 & Real & 2 & 1 & 0 & 2 & 8 & 4 & 12 \\
\hline Motor 3 & Real & 3 & 1 & 0 & 2 & 4 & 10 & 14 \\
\hline Fluorescent & Real & 4 & 2 & 0 & 1 & $\infty$ & 0 & 40 \\
\hline Halogen 1 & Real & 5 & 2 & 1 & 1 & $\infty$ & 0 & 40 \\
\hline Halogen 2 & Real & 6 & 2 & 1 & 1 & $\infty$ & 0 & 40 \\
\hline HVAC 1 & Simulated & 7 & 3 & 1 & 1 & 15 & 4 & 19 \\
\hline HVAC 2 & Simulated & 8 & 3 & 1 & 1 & 6 & 4 & 10 \\
\hline Water cooler & Real & 9 & 7 & 1 & 1 & 38 & 65 & 103 \\
\hline Cooker extractor & Simulated & 10 & 6 & 1 & 2 & 50 & 50 & 100 \\
\hline Refrigerator 1 & Real & 11 & 7 & 1 & 1 & 7 & 45 & 52 \\
\hline Washing machine & Real & 12 & 5 & 1 & 3 & 10 & 15 & 25 \\
\hline TV1 & Simulated & 13 & 4 & 1 & 3 & 40 & 0 & 40 \\
\hline Refrigerator 2 & Simulated & 14 & 7 & 1 & 1 & 10 & 40 & 50 \\
\hline Microwave & Simulated & 15 & 6 & 1 & 3 & 3 & 0 & 3 \\
\hline TV 2 & Simulated & 16 & 4 & 1 & 1 & 40 & 0 & 40 \\
\hline Kettle & Simulated & 17 & 6 & 1 & 3 & 10 & 0 & 10 \\
\hline Dishwasher & Simulated & 18 & 5 & 1 & 3 & 32 & 60 & 92 \\
\hline
\end{tabular}



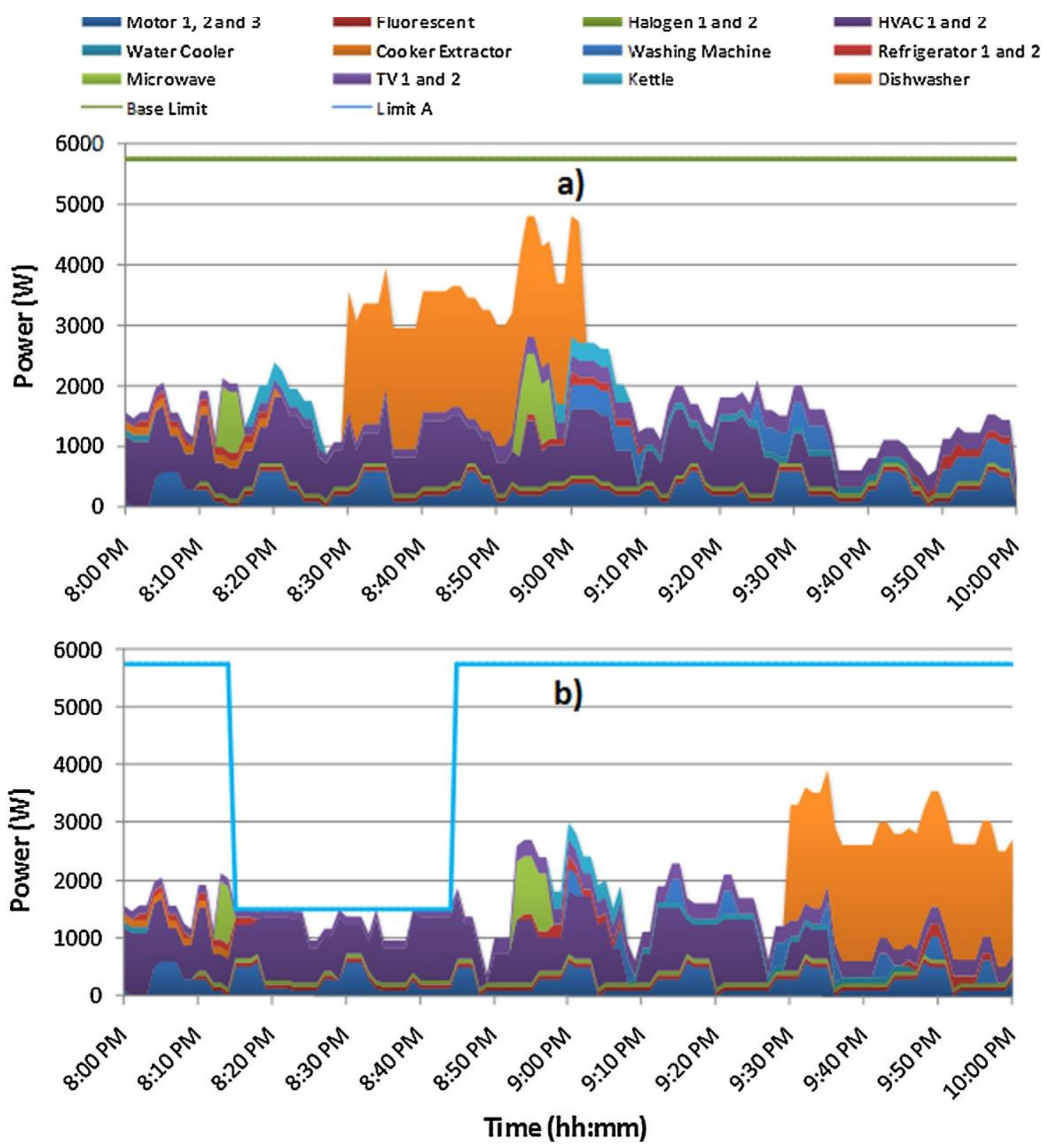

Fig. 8. Power consumption for each load in Base Scenario (a) and Scenario A with $30 \mathrm{~min}$ demand response event (b).

situations. The modules are grouped into three different parts, namely the Data acquisition, the Actuators, and the Intelligent Applications (Fig. 2).

- In the data acquisition part, four modules are included, namely the sensors, the user interfaces, the external communications, and the internal functions. The sensors module aggregates all types of sensors and meters in the house, and also in the devices inside the house. The user interfaces module allows the communication with different platforms, namely Windows, Android, and touch panels using the Modbus or TCP/IP protocol. The external interface allows the system remote access and the interaction with service providers' entities (in the existing platform this interaction is simulated in the MASGriP platform). The demand response events are introduced in the system through this module. The internal functions module integrates several functions in the SHIM system, such as the time synchronization. In the proposed methodology, the timesynchronization is important to run the optimization algorithm each minute. The internal functions module also integrates a negotiation function used to evaluate the participation in DR events, and a data acquisition function to determine comfort levels, the system efficiency, the estimated energy bill or the detection of abnormal functioning devices.

- A database was included to store all the information provided by other modules.

- The part of the actuators integrates all types of interfaces with real hardware, namely digital actuators, the analog actuators, inverters, motor drives, and among others. This module also includes the internal network management considering different protocols.

- The intelligent applications part integrates all the advanced functions in SHIM systems, namely the identification of the context, the definition of priorities, learning algorithms, the users' profiles identification, and the resources' management. The modules also need information on the equipment' functioning characteristics, and the actual status of each device. A trigger allows detecting new events to run all the algorithms. If the event was an order given by the user, the event trigger sends this order directly to the 


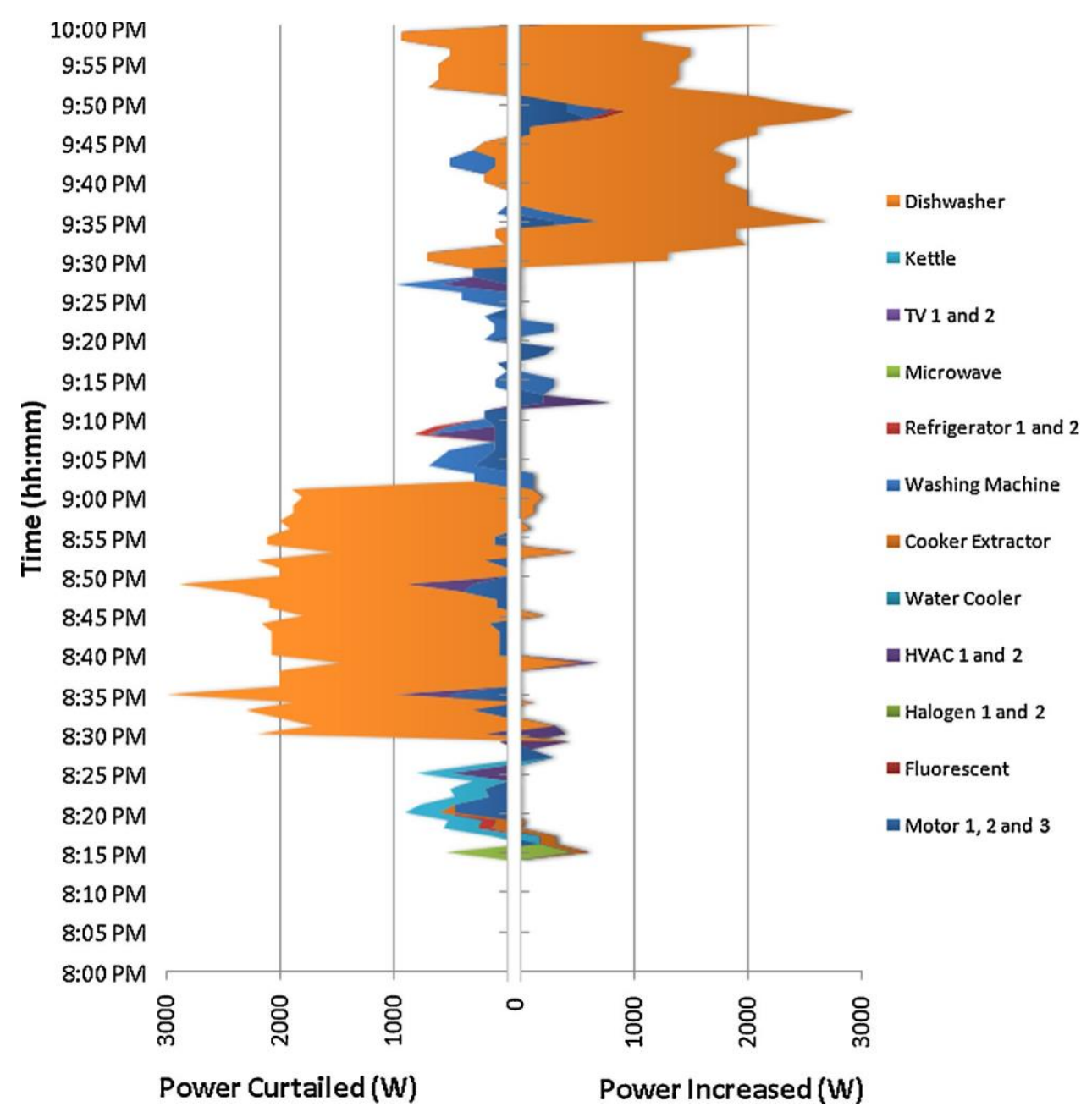

Fig. 9. The power consumption cut for Scenario A.

actuators, and in a second step, it sends the order to be processed by other modules. If the event was a demand response program, for example, the system does not need to execute any control action before the information is processed. With this mechanism, SHIM avoids delays between orders and actions.

\section{The SHIM system architecture is presented in Fig. 2.}

\subsection{Resources management module}

The resources management module allows an intelligent management of the energy consumption in a SHIM platform. The resources management module is activated by the event trigger, for instance when there is new information provided by sensors, changes in the power consumption limit or an external event, such as the demand response. The event trigger can also be activated by the time synchronization module in constant time intervals. In the first step, all the necessary data is collected, namely the resources priority in the present context, the power consumption limits imposed by users, by generation resources or by demand response events, the characteristics of the resources (power limits and time limits), and the actual status of each equipment. Then, the value of the actual power consumption and the imposed power limit are compared. If the power consumption is higher than the power limit, it is necessary to cut or to reduce the loads consumption.
An optimization algorithm tries to minimize the impact of the curtailments. Two regulation variables (regulation up and regulation down) are included to guarantee the problem feasibility. If the regulation down value was equal to 0 , it means that the optimization has obtained a good solution. If the regulation down value was higher than 0 , it means the optimization algorithm has obtained a solution with higher power consumption than the defined power consumptionlimit. Thisinformation should beprovided totheuser. If the user agrees with the solution, the system sends the order to the actuators. If the user not accepted, the solution should change manually the state of some loads or change the consumption limits. In this case, theSHIM intends this change as a new event, restarting the resources management process. The user's feedback can be provided by the touch panel or phone/tablet (the android application). If the user does not give any feedback, the system performs the optimization solution not considering to the demand response event. This procedure can be different in mandatory demand response events. The SHIM learning mechanism uses all the system/user interaction to adequate the system behavior to the user's profile.

The main reason for the regulation down variables being greater than 0 , is the existence of fixed loads managed by the users. Fixed loads cannot be managed by the system. An example of a fixed load can be a television; if the system detects people in the living room or an electric vehicle in charging process imposed by the user. If the system turns off the TV or stops the EV charging process will affect significantly the users' comfort level. The definition of the fixed loads depends on each context and on the users' profiles. In 
other words, the regulation down variable allows giving priority to comfort levels defined by the users in the participation in demand response events.

The regulation up variable is different from zero when the house power consumption is lower than the power consumption limit. In fact, when this situation happens, the optimization is not necessary. However, to ensure the algorithm robustness and to avoid unexpected situations, the regulation up variable is included in the problem formulation. Fig. 3 summarizes the architecture of the implemented resources management.

\subsection{Problem formulation}

The main goal of the optimization algorithm is to guarantee the electricity consumption limits $\left(P_{\text {Limit }}\right)$ during the house management system operation, considering different type of events, comfort levels, and the user's interaction. All these aspects are reflected in the resources and loads priority factors $\left(A_{\text {Load }}\right)$. The priority factors change between 0 and 10 , factor 10 being used for lower priority loads, and factor 0 for the highest priority loads. When the loads are not equipped with any actuator (uncontrollable) or when the users do not want the automatic device control, the corresponding power is included in the parameter $P_{\text {FixedLoads, }}$ and any priority is considered. The fixed loads change every optimization process during the DR event. The optimization problem can be formulated as follows:

Objective function to determine the loads that should continue in service:

$$
\text { Minimize } \left.f=\left\{\sum_{\text {Load }=1}^{\text {nLoad }} \lambda_{\text {Load }} \cdot P_{\text {Load }}+\lambda_{\text {Down }} \cdot \operatorname{Reg} \text { Down }+\lambda_{\text {Up }} \cdot \operatorname{Reg}\right\}_{\text {Up }}\right\}_{(1)}
$$

Eq. (2) intends to determine the connected load.

$$
P_{\text {Limit }}=P_{\text {Fixedloads }}+\sum_{\text {Load }=1}^{\text {nload }} P_{\text {Load }}+\operatorname{Reg}_{\mathrm{Up}}-\operatorname{Reg}_{\text {Down }}
$$

Eqs. (3) and (4) refer to the maximum and minimum limits of loads. If theload is discrete(On/Off), variable $P_{\text {Load }}^{M a x}$ is equal to $P_{\text {Load }}^{\mathrm{Min}}$ In this case, the decision is imposed by the binary variable $x_{\text {Load }}$.

$$
\begin{aligned}
& P_{\text {Load }} \leq P_{\text {Load }}^{\text {Max }} \times x_{\text {Load }} \\
& P_{\text {Load }} \geq P_{\text {Load }}^{\text {Min }} \times x_{\text {Load }}
\end{aligned}
$$

where

\begin{tabular}{ll}
\hline$A_{\text {Load }}$ & Load priority \\
\hline$A_{\text {Down }}$ & Regulation down priority \\
$A_{\mathrm{Up}}$ & Regulation up priority \\
Load & Load index (ID) \\
$n$ Load & Maximum number of loads \\
$P_{\text {Load }}^{\text {Max }}$ & Maximum load consumption $[\mathrm{W}]$ \\
$P_{\text {Load }}^{\text {Min }}$ & Minimum load consumption $[\mathrm{W}]$ \\
$P_{\text {FixedLoads }}$ & Total consumption of non-controlled loads $[\mathrm{W}]$ \\
$P_{\text {Limit }}$ & Power limit for the total consumption $[\mathrm{W}]$ \\
$P_{\text {Load }}$ & Power consumption of load $[\mathrm{W}]$ \\
$\operatorname{Re} g_{\text {Down }}$ & Power regulation down $[\mathrm{W}]$ \\
$\operatorname{Re} g_{\mathrm{Up}}$ & Power regulation up $[\mathrm{W}]$ \\
$x$ Load & Load binary variable \\
\hline
\end{tabular}

\subsection{Dynamic loads priority method}

In the previous work, loads priorities are defined according to the comfort levels in each context, and considering the user's profiles [31]. To participate in DR events, SHIM should cut some loads
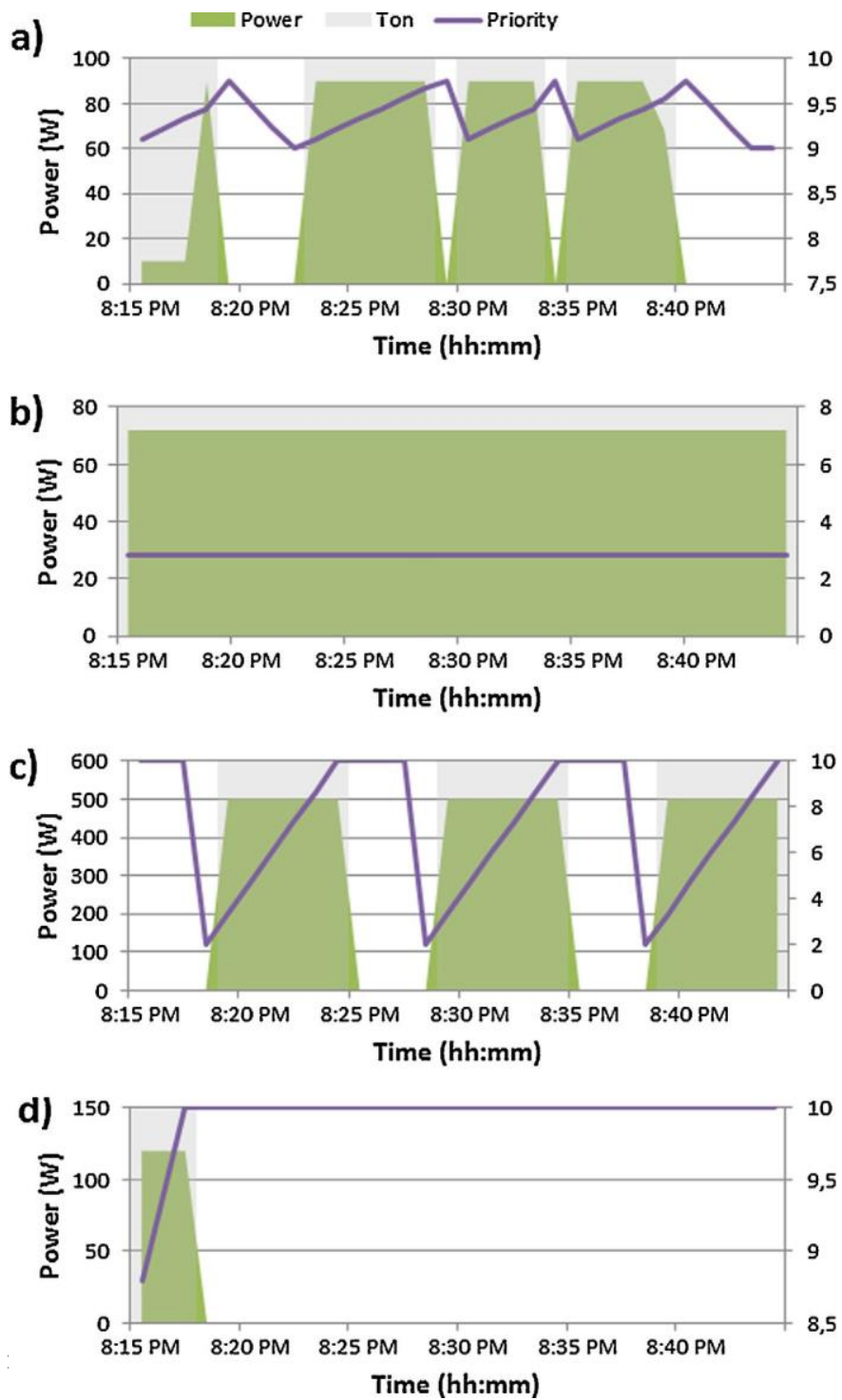

nario $A$ for motor 1 (a), fluorescent (b), HVAC 2 (c) and refrigerator 2 (d).

\section{during the events. However, some loads like refrigeratorscanngt
be diseonnected for a coupleof hours. In this way, ifis necessary to}

have a dynamic loads priority (DLP) variation during the demand responseevent, avoiding the disconnectionfrom theseloadsduring long periods. Each load can be characterized by the Toff max - the maximum time (in minutes) that each load can be turned off, and by the Ton max - the maximum time (in minutes) that each load can be turned on. Toff max can be seen as the maximum delay to turn on the loads, and Ton max can be seen as the maximum delay to turn off the loads.

For example, in the case of the heating, ventilation, and air conditioning unit (HVAC), this type of load do not need to be on all the time. It may be on for $10 \mathrm{~min}$, and off for $5 \mathrm{~min}$. The same happens with the refrigerators. According to the system database, the refrigerator presents the load profile of Fig. 4 . The refrigerator is on for $11 \mathrm{~min}$ (between 8:33 PM and 8:44 PM), and off for $52 \mathrm{~min}$ (between 8:44 PM and 9:36 PM).

The methodology developed, proposes the variation of the load priority factor $A_{i}$ provided by the priorities definition module, considering the on/off time of the appliances. In the optimization process, it is considered a new factor $A_{f}$ obtained from the initial load priority factor $A_{i}$, and factor $(k)$ that depends on the on/off time. 

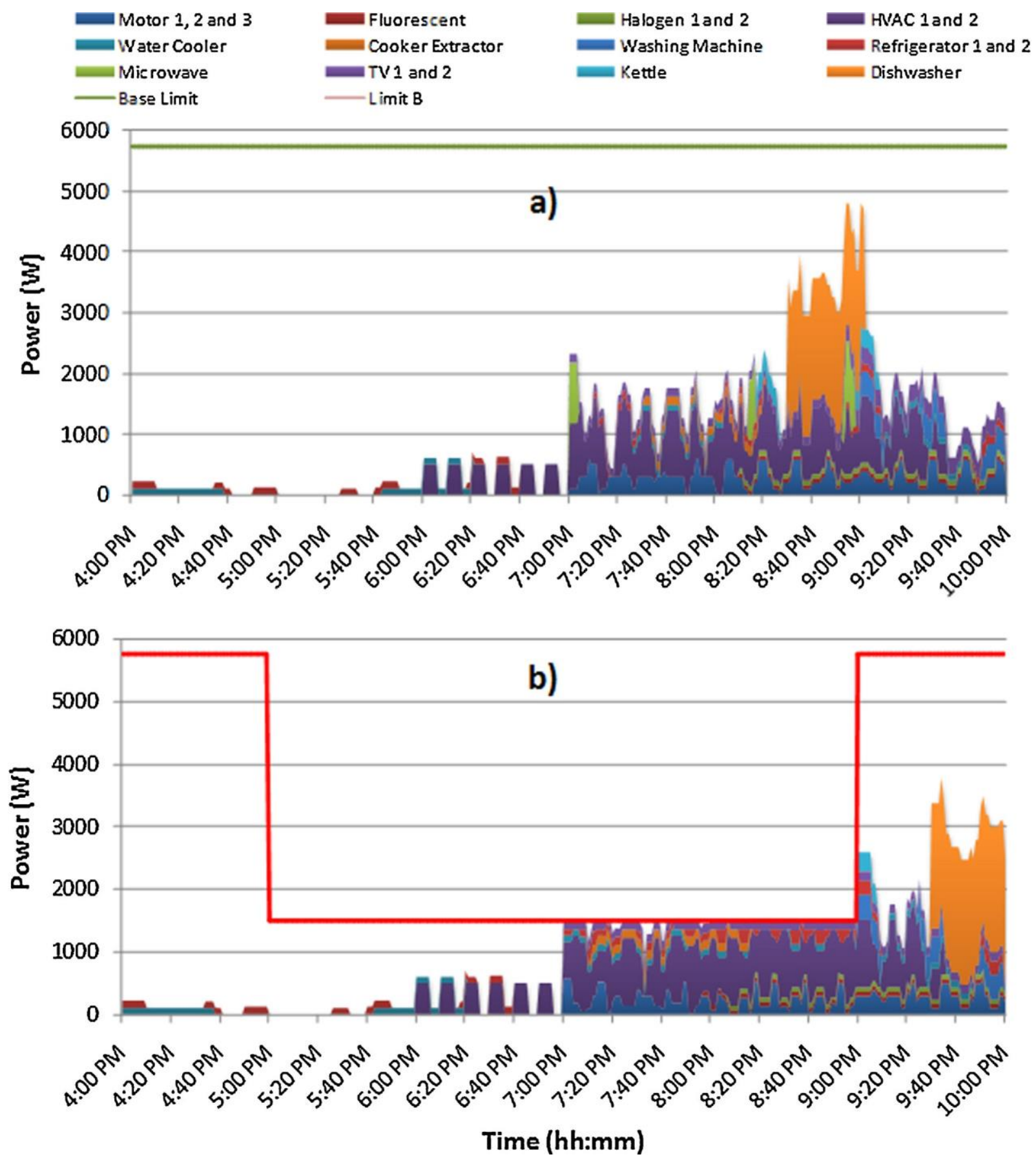

Fig. 11. Power consumption for each load in the Base Scenario (a) and Scenario B with demand response event of $4 \mathrm{~h}$ (b).

After the optimization process, the system will evaluate the state of each load. If the load was turned off, value $k$ will be decreased, decreasing the priority factor in the next optimization. If factor $k$ was less than 0 , the system can consider the load as a fix load off, blocking the automatic control in the next optimization. On the other hand, if the load is connected and factor $k$ was higher than 1 , the system can consider the load as a fix load on, blocking the automatic control. If the load is on, factor $k$ will be increased, increasing also the priority factor in the next optimization. Fig. 5 shows the proposed mechanism.where

\begin{tabular}{ll}
\hline$A_{i}$ & Load priority \\
$A_{f}$ & New load priority \\
Load & Load index (ID) \\
$n$ Load & Maximum number of loads \\
$k$ & Load priority factor \\
fixedOn & Non-controlled loads On \\
fixedOff & Non-controlled loads Off \\
$T_{\text {On }}$ & Load time On \\
$T_{\text {On-max }}$ & Maximum load timeOn \\
$T_{\text {Off }}$ & Load time Off \\
$T_{\text {Off_max }}$ & Maximum load time Off \\
\hline
\end{tabular}




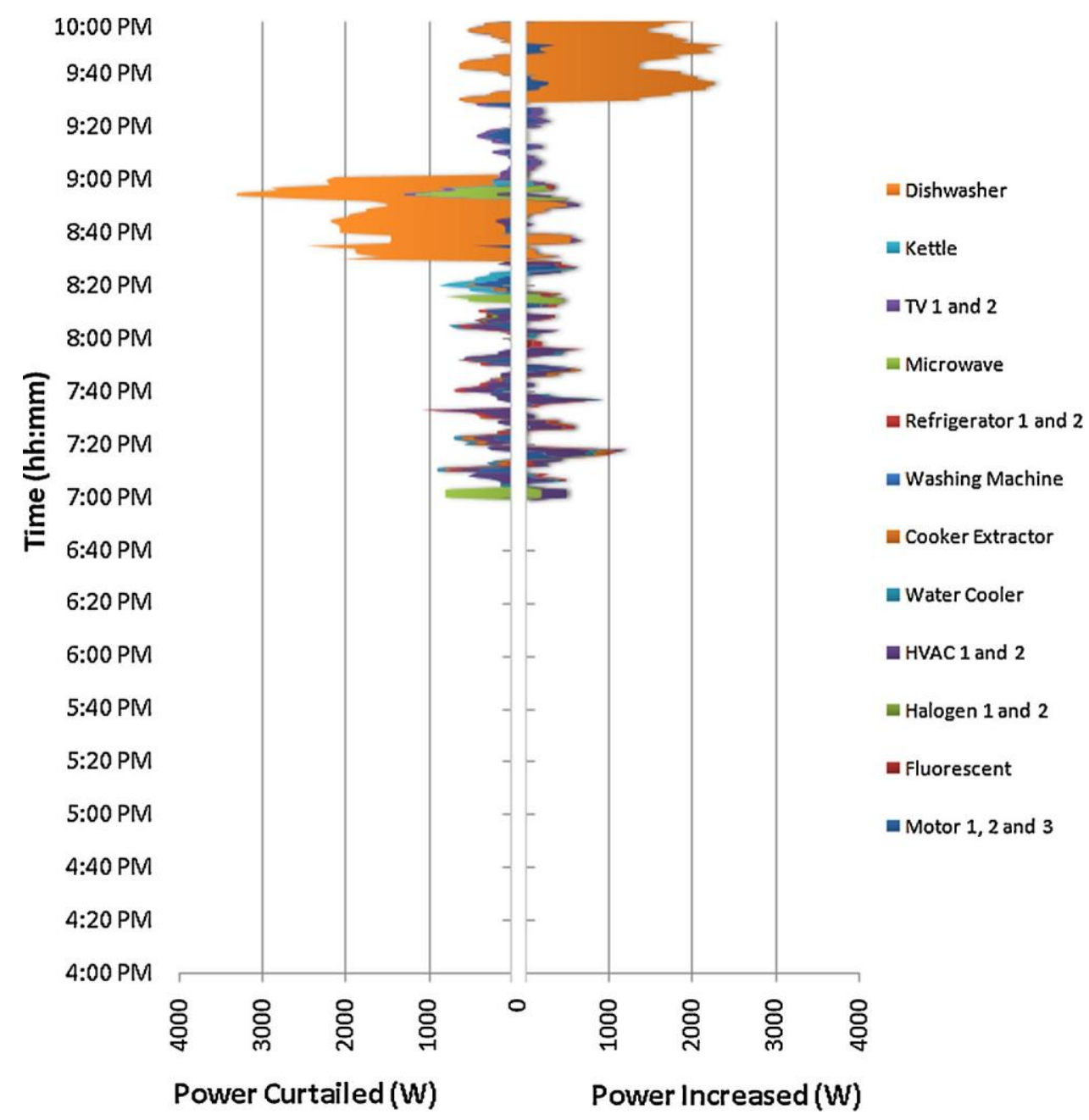

Fig. 12. The power consumption cut for Scenario B.

\section{Case study}

The present case study intends to illustrate the proposed methodology during a demand response event. Two different scenarios are tested considering a demand response of $30 \mathrm{~min}$, and another with $240 \mathrm{~min}(4 \mathrm{~h})$. In both simulations, the demand response event proposes the power consumption reduction during the event.

Domestic consumers have different types of loads with different use features. Thus, in this case study the profiles of typical domestic appliances, such a refrigerator, washing machine, HVAC, and among others, are considered. Several aspects are taken into account such as the power consumption, the amount of time the load is on or off, the priority for each load, the loads which can be turned off (non-priority loads), the type of control for each load (variable or discrete), and the type of load (lights, motors, HVAC, etc.). A total of 18 loads are used, including real and virtual ones, controlled by the SHIM system.

\subsection{Loads characteristics}

Aspreviously mentioned, thecasestudyconsiders realloadsand virtual ones in the same simulation. The virtual loads are implemented considering the data collected in real appliances and saved on database. Actually, in the data base it is possible to obtain the consumption profile of different appliances and devices such as refrigerators, microwaves, washing machines, water coolers, and HVAC.

The loads are characterized in the resources management module considering different aspects. In Fig. 6 some characteristics are summarized. In Table 1, the used loads are classified according to the characteristics of theloads.

\subsection{Scenarios description}

In the present case study, two scenarios with different demand response time duration are shown. Both scenarios are compared with the scenario without the demand response event (Base Scenario). The power consumption in the Base Scenario is presented in Fig. 7, considering the loads characteristics indicated in subsection 4.1. The power consumption limit in the Base Scenario is of $5.9 \mathrm{~kW}$. This value is provided by the use context module. However, during the demand response event the power consumption limit is reduced to $1.5 \mathrm{~kW}$ during $30 \mathrm{~min}$, starting at 8:15 PM in Scenario $A$ (Line blue in Fig. 7), and during $240 \mathrm{~min}$, starting at 5:00 PM in Scenario B (Line red in Fig. 7).

\subsection{Scenario A-results}

The results obtained in Scenario $A$ are presented and discussed in the present subsection.

In Fig. 8 the desegregated consumption of the appliances between 8:00 PM and 10:00 PM is presented. On the top of Fig. 8, 
one can see the power consumption in the Base Scenario, and on the bottom part, the consumption considering the demand response event between 8:15 PM to 8:45 PM.

As it is possible to see in this figure, the system keeps the power consumption below the imposed limit $(1500 \mathrm{~W})$ during the demand responseevent. After the demand responseevent, theconsumption profile is different when compared with the Base Scenario. In Fig. 9 it is possible to see in more detail the power consumption differences between the Base Scenario and Scenario A. In this figure, the values on the left side represent the consumption reduction, and the values on the right side represent the increase in consumption. In some periods the consumption increases in some loads, to be decreased in more critical periods. This way, it is possible to ensure the consumption limit during the event. Some loads, the washing machine for example, are postponed to a period after the demand response event, increasing significantly the consumption after 9:30 PM.

To verify the effectiveness of the DLP method, Fig. 10 presents the results of the application method for Scenario A considering four loads with characteristics presented in subsection 4.1:

- Motor 1 (motor type, variable control, and essential load, Ton: 9, Toff: 4)

- Fluorescent (light type, variable control, and permanent load, Ton: $\infty$, Toff: 0 )

- HVAC2(HVAC type, discrete control, and permanent load, Ton: 6, Toff: 4)

- Refrigerator 2 (cooler type, discrete control, and permanent load, Ton:10, Toff: 40)

According to Fig. 10, it is important to analyse the results that depend on the loads characteristics. The priority factors change between 0 and 10, the factor 10 being used for the lowest priority loads and factor 0 for the highest priority ones. According to (1), the optimization process tries tominimize the product $A_{\text {Load }} \cdot P_{\text {Load }}$. This means that the loads with lower $A_{\text {Load }}$ factor will still be connected. The analysis for each load priority in Scenario $A$ is as follows:

- Motor 1 (ID Load 1): priority is between 9 and 10 for the demand response event (it is never 10). The duration of the state on or state off depends on the priority value of the others loads (Fig. 10a).

- Fluorescent (ID Load 4): priority is constant due to its characteristics. Lights can be on the entire time, not requiring to be disconnected. In practice, factor $k$ is always equal to 0 , and the final load priority factor $A_{f}$ is equal to the initial load priority factor Ai (Fig. 10b).

- HVAC 2(ID Load 8): is the constant load according to the reference mode of the load. The load is on for $6 \mathrm{~min}$, and off for $4 \mathrm{~min}$. The load priority factor changes fast from 10 to 2 when the load is disconnected for more than $4 \mathrm{~min}$ (Fig. 10c).

- Refrigerator 2 (ID Load 14): at the beginning of the DR event, the refrigerator is already on for $7 \mathrm{~min}$. The management system, according to priorities values, keeps Refrigerator 2 on at the end of the cycle on (to $10 \mathrm{~min}$ ). After these $10 \mathrm{~min}$, the priority value is the maximum (10), so the load is turned off and kept off at the end of the DR event because of the functioning cycle of the refrigerator (Fig. 10d).

\subsection{Scenario B-results}

In Scenario B, an optimization process for a DR event of $240 \mathrm{~min}$ with the same power limit of Scenario $A$ is considered. Fig. 11 represents the load profile of the domestic consumer between 4:00 PM and 10:00 PM, with detailed consumption for each load in Scenario $B$, and the results of the DR event comparing with the Base Scenario without powerlimit.
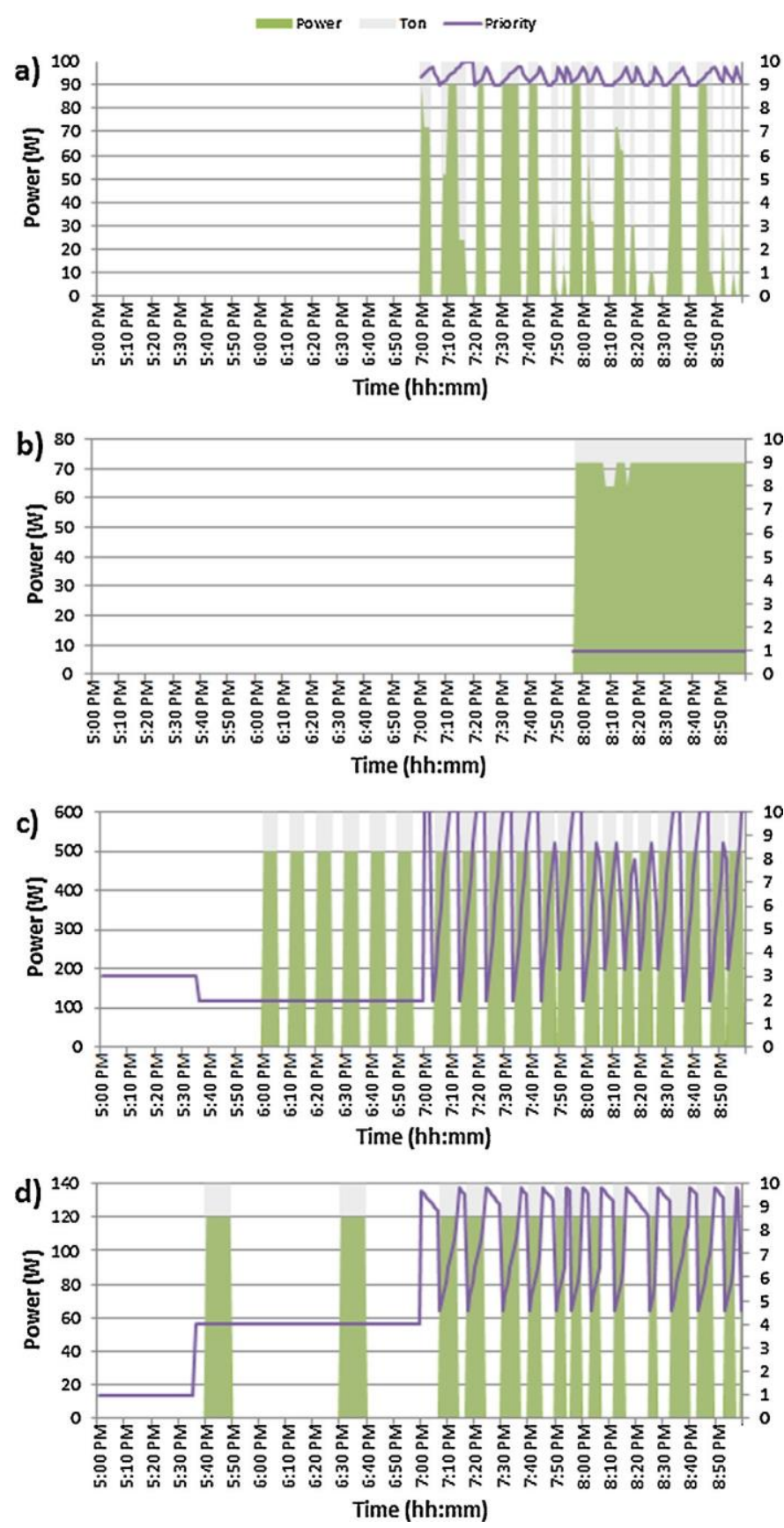

Fig. 13. Results of the dynamic loads priorities on the demand response event for Scenario $B$ for motor 1 (a), fluorescent (b), HVAC 2 (c) and refrigerator 2 (d).

As it is possible to see in Fig. 11, the optimization results also meet the power limit $(1500 \mathrm{~W})$ during the demand response event. The use profile changes significantly at 7:00 PM due to the presence of people in the house. The load scheduling between 5:00 PM and 7:00 PM does not require any load curtailment or reduction. However, between 7:00 PM and 9:00 PM the system needs to manage effectively the load curtailment. The loads' consumption increase and decrease, comparing with the Base Scenario, as one can see in detail in Fig. 12.

Fig. 13 presents some results for Scenario $B$ between 5:00 PM and 8:59PMlike the priority, time on or off, and the power consumption for each minute. In this case, the maximum time on or time off in some cases is not showed due the higher value (for example, for values higher than 20 or $40 \mathrm{~min}$, depending on the case). 
In Fig. 13 it is possible to see the evolution of the load priority for each load, and also the power consumption. The same assumptions of Fig. 10 regarding the load priority factors were considered. The load represented in Fig. 13 (a) is only connected at 7:00 PM, and the load represented in Fig. 13 (b) is only connected at 8:00 PM. Therefore, the priority factor is not considered in the optimization process. The differences in the load priorities during the event are changed by the use contexts changes. These differences can be seen in Fig. 13 (c) and (b) at 5:30 PM. During the demand response event, the evolution of load priorities is similar to Scenario A.

\subsection{Case study conclusions}

The case study allows the proposed methodology evaluation in two different scenarios. In the first scenario, a 30-min demand response event is considered, and in the second scenario a 240min event is considered. In both cases, the system ensures the power limit imposed during the event, in the case $1500 \mathrm{~W}$. The main change is in the washing machine. This appliance is postponed in both scenarios. However, if theuser wants touse it during theevent, the system could not maintain the power consumption lower than the limit. Other important aspect is the use of the lights. The users easily detect the lightning variations in the lights. In the present simulation, the system does not change or disconnect the lights in Scenario $A$, and in Scenario $B$ a small variation is considered for a few minutes.

Despite these considerations, the methodology presents good results in the load management mainly in the demand response events of long duration. Other important aspect is that the used power limit $(1500 \mathrm{~W})$ is extremely hard to guarantee during long periods, and in both simulated scenarios, the system guarantees this consumptionlimit.

\section{Conclusions}

The energy management of end consumers has strong relevance in the future power systems, mainly in smart grids and microgrids operation context. This paper focuses on energy management methodology in real-time to obtain new solutions for the domestic consumers in order to contribute with new approaches for the power systems. It is important to identify, within domestic consumers, the influence that each load has in power consumption, and how the management methodology influences the total consumption of the domestic consumer taking into account the grid and house conditions.

In this paper a dynamic load priority (DLP) method is proposed to change the load priority during a demand response event. The DLP use the load priority provided by the use contextidentification module, changing this priority according to the technical characteristics of each load. Different loads characteristics are considered, namely the lights, washing machines, etc. Load priorities of each load are used by the optimization module to determine the least important load in each instant. The loads priorities are analyzed every minute or when some control actions are taken by the users. The propose methodology allows obtaining a more efficient load management mainly during the demand response events of long duration.

A case study considering two scenarios is presented to validate the developed methodology. In these scenarios good results were obtained, even considering a very low power consumption limit. However, it is important that the users agree with the implemented strategies mainly in the case of appliances, such as washing machines due to the high power consumption.

\section{Acknowledgments}

This work is supported by FEDER Funds through COMPETE program and by National Funds through FCT under the projects FCOMP-01-0124-FEDER: PEst-OE/EEI/UI0760/2014, and PTDC/SEN-ENR/122174/2010, and by the GID-MicroRede, project no. 34086, co-funded by COMPETE under FEDER via QREN Programme, and by the SASGER-MeC, project no. NORTE-07-0162FEDER-000101, co-funded by COMPETE under FEDER Programme.

The research leading to these results has received fund-ing from the People Programme (Marie Curie Actions) of the European Union's Seventh Framework Programme FP7/2007- 2013/under project ELECON - Electricity Consumption Analysis to Promote

Energy Efficiency Considering Demand Response and Nontechnical Losses, REA grant agreement no 318912 (PIRSES-GA2012-318912).

Hugo Morais is funded from The Danish Council forStrategic Research under grant agreement no. 11-116794.

\section{References}

[1] K. Kok, S. Karnouskos, D. Nestle, A. Dimeas, A. Weidlich, C. Warmer, P. Strauss, B. Buchholz, S. Drenkard, N. Hatziargyriou, V. Lioliou, Smart houses for a smart grid, in: 20th International Conference on Electricity Distribution, CIRED 2009, 2009, pp. 1-4.

[2] S.K. Das, D.J. Cook, A. Battacharya, E.O. Heierman, The role of prediction algorithms in the MavHome smart home architecture, IEEE Wireless Communications 9 (6) (2002) 77-84.

[3] Wi Young-Min, Lee Jong-Uk, Joo Sung-Kwan, Electric vehicle charging method for smart homes/buildings with a photovoltaic system, IEEE Transactions on Consumer Electronics 59 (2) (2013) 323-328.

[4] Li Jiang, Da-you Liu, Bo Yang, Smart home research, in: Proceedings of 2004 International Conference on Machine Learning and Cybernetics, IEEE Cat. No.04EX826, vol. 2, 2004, pp. 659-663.

[5] Y. Fei, B. Jiang, Dynamic residential demand response and distributed generation management in smart microgrid with hierarchical agents, Energy Procedia 12 (2011) 76-90.

[6] N. Roy, A. Roy, S. K Das, Context-aware resource management in multiinhabitant smart homes: a nash H-learning based approach, in: Fourth Annual IEEE International Conference on Pervasive Computing and Communications, PERCOM'06, 2006, pp. 148-158.

[7] G. Wood, M. Newborough, Energy-use information transfer for intelligent homes: enabling energy conservation with central and local displays, Energy and Buildings 39 (2007) 495-503.

[8] J. Ye, Q. Xie, Y. Xiahou, C. Wang, The research of an adaptive smart home system, in: 2012 7th International Conference on Computer Science \& Education (ICCSE), 2012, pp. 882-887.

[9] F. Fernandes,H.Morais,P.Faria, Z.Vale,C. Ramos, SCADA houseintelligentmanagement for energy efficiency analysis in domestic consumers, in: 2013 IEEE PES Conference on Innovative Smart Grid Technologies (ISGT Latin America), 2013.

[10] P. Oliveira, T. Pinto, H. Morais, Z. Vale, MASGriP - A multi-agent smart grid simulation platform, in: IEEE Power and Energy Society General Meeting, 2012, pp. $1-8$.

[11] M. Samadi, M.H. Javidi, M.S. Ghazizadeh, The effect of time-based demand response program on LDC and reliability of power system, in: 2013 21st Iranian Conference on Electrical Engineering (ICEE), 2013, pp. 1-6.

[12] S.P. Borg, N.J. Kelly, The effect of appliance energy efficiency improvements on domestic electric loads in European households, Energy and Buildings 43 (9) (2011) 2240-2250.

[13] Y.Si, J.T. Kim, I.Y.Choi, S.H. Cho, Energy consumption characteristics of high-rise apartment buildings according to building shape and mixed-use development, Energy and Buildings 46 (2012) 123-131.

[14] L.G. Swan, V.I. Ugursal, Modeling of end-use energy consumption in the residential sector: a review of modeling techniques, Renewable and Sustainable Energy Reviews 13 (8) (2009) 1819-1835.

[15] D. Bonino, F. Corno, L. De Russis, Home energy consumption feedback: a user survey, Energy and Buildings 47 (2012) 383-393.

[16] N.E. Ryan, J.T. Powers, S.D. Braithwait, B.A. Smith, Generalizing direct load control program analysis: implementation of the duty cycle approach, IEEE Transactions on Power Systems 4 (1) (1989) 293-299.

[17] K.P. Wacks, Utility load management using home automation, IEEE Transactions on Consumer Electronics 37 (2) (1991) 168-174.

[18] H.B. Stauffer, Smart enabling system for home automation, IEEE Transactions on Consumer Electronics 37 (2) (1991) xxix-xxxv.

[19] N. Kushiro, S. Suzuki, M. Nakata, H. Takahara, M. Inoue, Integrated residential gateway controller for home energy management system, IEEE Transactions on Consumer Electronics 49 (3) (2003) 629-636. 
[20] M. Inoue, T. Higuma, Y. Ito, N. Kushiro, H. Kubota, Network architecture for home energy management system, IEEE Transactions on Consumer Electronics 49 (3) (2003) 606-613.

[21] C. Lien, Y. Bai, M. Lin, Remote-controllable power outlet system for home power management, IEEE Transactions on Consumer Electronics 53 (4) (2007) 1634-1641.

[22] M. Lee, Y. Uhm, Y. Kim, G. Kim, S. Park, Intelligent power management device with middleware based living pattern learning for power reduction, IEEE Transactions on Consumer Electronics 55 (4) (2009) 2081-2089.

[23] Q. Liu, G. Cooper, N. Linge, H. Takruri, R. Sowden, DEHEMS: creating a digital environment for large-scale energy management at homes, IEEE Transactions on Consumer Electronics 59 (1) (2013) 62-69.

[24] R.J. Meyers, E.D. Williams, H.S. Matthews, Scoping the potential of monitoring and control technologies to reduce energy use in homes, Energy and Buildings 42 (5) (2010) 563-569.

[25] P. Faria, Z. Vale, Demand response in electrical energy supply: an optimal real time pricing approach, Energy 36 (8) (2011) 5374-5384.

[26] M. Kuzlu, M. Pipattanasomporn, S. Rahman, Hardware demonstration of a home energy management system for demand response applications, IEEE Transactions on Smart Grid 3 (4) (2012) 1704-1711.
[27] Y. Ozturk, D. Senthilkumar, S. Kumar, G. Lee, An intelligent home energy management system to improve demand response, IEEE Transactions on Smart Grid 4 (2) (2013) 694-701.

[28] G.T. Costanzo, G. Zhu, M.F. Anjos, G. Savard, A system architecture for autonomous demand side load management in smart buildings, IEEE Transactions on Smart Grid 3 (4) (2012) 2157-2165.

[29] M. Pipattanasomporn, M. Kuzlu, S. Rahman, An algorithm for intelligent home energy management and demand response analysis, IEEE Transactions on Smart Grid 3 (4) (2012) 2166-2173.

[30] Y. Li, B.L. Ng, M. Trayer, L. Liu, Automated residential demand response: algorithmic implications of pricing models, IEEE Transactions on Smart Grid 3 (4) (2012) 1712-1721.

[31] L. Gomes, F. Fernandes, T. Sousa, M. Silva, H. Morais, Z. Vale, C. Ramos, Contextual intelligent load management with ANN adaptive learning module, in: 16th International Conference on Intelligent System Applications to Power Systems, 2011, pp. 1-6. 